\title{
A Study of Prevalence and Financial Loss of Cysticercus Tenicollis in Visceral Organ of Sheep Slaughtered at Jimma Municipal Abattoir,Southwest Ethiopia
}

\author{
Tsegaye Fikru ${ }^{1} \quad$ Misgana Bekele ${ }^{2}$ \\ Jimma University College of Agriculture and Veterinary Medicine, P.O.B: 307, Jimma, Ethiopia
}

\begin{abstract}
A cross-sectional study was carried out from November 2015 to March 2016 on a total of 384 sheep slaughtered at Jimma municipal abattoir to determine the prevalence and estimate direct financial loss due to Cysticercus tenuicollis. Ante-mortem examinations and post-mortem organ inspections were performed following standard procedures. A total of 205 animals were found positive for Cysticercus tenuicollis with an overall prevalence of $53.4 \%(95 \% \mathrm{CI}=48.0-58.0)$ with a significant difference $(\mathrm{p}=0.000)$ between age groups which was higher in adult animals than in younger age groups. The relative cyst distribution in visceral organs was higher in omentum $(38.0 \%)$ followed by liver $(25.5 \%)$ with an estimated financial loss of 21528 ETB from liver condemnation. This study revealed that the occurrence of high prevalence of Cysticercus tenuicollis in sheep slaughtered at Jimma abattoir with a significant financial loss which deserve proper disposal of affected organs and implementation of parasite control programs in the area.
\end{abstract}

Keywords: Prevalence, Cysticercus tenuicollis, Sheep, Jimma, Ethiopia.

DOI: $10.7176 / \mathrm{JHMN} / 89-03$

Publication date:May $31^{\text {st }} 2021$

\section{INTRODUCTION}

Ethiopia is the second in Africa, and the sixth in the world, in terms of sheep population. In spite of huge population and importance of small ruminants, the country has benefited little from this enormous resource owning to a multitude of problems like poor nutrition, poor animal production systems, reproductive inefficiency, management constraints, lack of veterinary care, and disease being the most important (Sisay, 2007). Parasitic diseases in the tropics are responsible for great losses in the meat industry than any other infectious or metabolic disease (Perry et al., 2002). Like many other African countries, it is known that liver fluke, Hydatid cyst and Cysticercus teniucollis are major parasites responsible for low productivity in Ethiopia livestock industry due to imposing poor weight gains and condemnation of organs and carcass of sheep and goats (Abebe, 1995). Infections with the larval stage of some species of Taenia are of veterinary importance, because they cause economic losses due to condemnation of infected offal or meat (Radfar et al., 2005), From this taenia species, Cysticercus tenuicollis is the most important parasite of sheep and goats (Yehualashet et al., 2012), which causes organ condemnation from slaughter houses (Radostits et al., 2007).

Cysticercus tenuicollis is the larval stage of the canine tapeworm Taenia hydatigena. This cestode has been found in a large number of hosts throughout the world (Senlik, 2008). The intermediate host becomes infected by ingesting proglottids or eggs passed in the feces of the dog in pastures or feeding areas. After ingestion, the egg's shell is digested and the oncospheres become free to migrate through the intestinal walls, reaching the liver through the hepatic portal system. The oncospheres may remain in the liver or migrate to different part of the body and the cysts are most commonly found attached to the omentums, mesenteries, liver and peritoneum (Radostits et al., 2007).

Normally, infection with Taenia hydatigena is not very pathogenic in dog (Radfar et al., 2005) and infection of small ruminants with cysticerci of Taenia hydatigena is frequently not significant and the effect of this infestation upon the hosts depends largely on the degree of the parasitism, the organs involved and the existence of other concurrent infections (Urquhart et al., 1996; Wondimu et al., 2011).

The prevalence of Cysticercus tenuicollis is quite common and considerably high in the world and in some countries even more than $85 \%$ of the sheep population was found to be infected with this metacestode (Senlik, 2008). However, the prevalence varies from one area to another. Generally, there is higher incidence in countries with lower degree of sanitary and uncontrolled wild carnivore population (Budka et al., 2004).

In Jimma town, in the southwestern part of Ethiopia, the hygienic conditions are poor. Backyard slaughtering of domestic animals, particularly, sheep and goats; and feeding of stray dogs with condemned organs are common practices (Abduljewad, 1988). Despite this, in the study area there was no so far study was conducted on the prevalence and financial loss of Cysticercus tenuicollis in sheep.

Therefore, the aims of this study were;

- To determine the prevalence of Cysticercus tenuicollis in sheep slaughtered at Jimma municipal abattoir.

- To assess the direct financial loss due to liver condemnation in the abattoir. 


\section{MATERIALS AND METHODS}

\subsection{Descriptions of Study Area}

The study was conducted in jimma municipal abattoir in jimma town, oromia national regional state, south western Ethiopia. Jimma town is located at $352 \mathrm{~km}$ south western of Addis Ababa. Geographically, Jimma is located at $7^{\circ} 13^{\prime}$ and $8^{0} 56^{\prime} \mathrm{N}$ latitude and $35^{\circ} 52^{\prime}$ and $37^{\circ} 37 \mathrm{E}$ longitude. The climatic condition of the area is 'Woynadega' with altitude ranging between 1720 to $2110 \mathrm{~m}$ above sea level and receives annual rainfall which ranges between 1200 to $2000 \mathrm{~mm}$. There are two rain seasons, short rainy season (November to April) and long rainy season (July to October). The annual mean temperature ranges from about $12.1^{\circ} \mathrm{C}$ to $28^{\circ} \mathrm{C}$ (JZARDO, 2009). Jimma zone has a livestock population of about 2016823 (cattle), 942908 (Sheep), 288411 (Goats), 74574 (Horses), 49489 (Donkeys), 28371 (Mules) and 1139735 (Poultry) (CSA, 2009).

\subsection{Study population}

The study was conducted on sheep with different age of indigenous breed and all male slaughtered at Jimma municipal abattoir. The exact origins of all animals were unknown, even the suppliers themselves does not know the exact origin of all sheep, but most of from different local market of Jimma town and the surrounding nearest Districts. Slaughtered animals reached at Jimma municipal abattoir by transporting using vehicles. In this study, sheep were categorized into two age groups, young and adult, Sheep with the first pair of permanent incisor teeth were considered as young and those with two and more pair of permanent incisors were regarded as adults according to the guidelines set by (Getanby, 1991).

\subsection{Study Design}

A cross sectional study was conducted from November 2015 to March 2016 by collecting data on events associated with $C$. tenuicollis in sheep slaughter at jimma municipal abattoir.

\subsection{Sampling}

3.4.1. Sample size determination: The sample size required for this study was determined according to (Thrusfield, 2005) formula.

$$
\mathrm{N}=\frac{1.96^{2} \times \mathrm{P}_{\exp }\left(1-\mathrm{P}_{\exp }\right)}{\mathrm{d}^{2}}
$$

Where, $\mathrm{N}=$ required sample size

$\mathrm{P}_{\text {exp }}=$ expected prevalence and

$\mathrm{d}=$ desired absolute precision

There was no previous study on prevalence of $C$. tenuicollis in sheep in the study area. Therefore, an expected prevalence of $50 \%$ was used to estimate the sample size. Using desired $95 \%$ confidence interval, $5 \%$ precision, the number of sheep needed to determine the prevalence of $C$. tenuicollis in the study area was calculated to be 384.

3.4.2. Sampling method

The study animals were selected from the slaughter line at time of postmortem examination using simple random sampling technique after serial number given during ante-mortem examination according to their arrival.

\subsection{Study Methodology}

\subsubsection{Ante-mortem inspection}

Pre-slaughter examinations were conducted in the lairage in order to determine the age group. Serial number was also given to each animal to examine after evisceration. During ante-mortem examination animals were clinically examined for any sign of illness while standing and moving according to Urquhart et al. (1996) and followed the judgments passed by FAO (1994). Animals suspected for any disease conditions during antemortem examination were excluded from sampling.

\subsubsection{Post-mortem examination}

During post-mortem examination, visceral organs were thoroughly inspected by applying the routine meat inspection procedures involving visualization, palpation and systematic incisions for the presence of parasites and other abnormalities, paying attention to the visceral organs and tissues in abdominal, thoracic and pelvic cavities (Herenda et al., 2000).

\subsection{Assessment of Financial Loss}

An attempt was made in order to estimate economic significance of Cysticercus tenuicollis in sheep from the cost of condemned liver. To calculate the economic loss, the following parameters were taken into consideration; The mean market price of single liver at Jimma town was collected from butchers, the rejection rates of liver and Average annual slaughter rate of sheep at the abattoir was estimated based on observation during the study period together with the judgment of senior meat inspectors of the abattoir. The economic loss due to liver 
condemnation was estimated by the formula set by (Ogunrinade and Ogunrinade, 1980) as follows:

$\mathrm{EL}=\Sigma \mathrm{Srx} \times \mathrm{Coy} \times \mathrm{Roz}$

Where, $\mathrm{EL}=$ Annual economic loss estimated due to liver condemnation from local market.

Srx = average annual sheep slaughter rate of the abattoir

Coy $=$ Average cost of each sheep liver

Roz $=$ Condemnation rates of sheep liver

\subsection{Data Management and Analysis}

Data collected were entered into Microsoft excel spreadsheet and analyzed. All the data analysis was done by Statistical Package for Social Science (SPSS) software version 20. Pearson's chi-square $\left(\mathrm{x}^{2}\right)$ was used to evaluate the association present among the different age group. P-value less than 0.05 (at 5\% level of significance) were considered as significant. Descriptive statics such as percentages and frequency distribution were used to describe the nature and the characteristics of the data

\section{RESULTS}

Out of a total of 384 sheep slaughtered and examined during November 2015 to March 2016 at Jimma municipal abattoir 205(53.4\%) of animals were found harbouring Cysticercus tenuicollis in one or more of their visceral organs (Table 1). $0.000)$.

The prevalence of $C$. tenuicollis was significantly higher in adult sheep than in the young age group $(\mathrm{P}=$

In this study different visceral organs were affected with $C$. tenuicollis in which a single or multiple organs were involved. Among the visceral organs omentum was widely affected constituting $38.0 \%$. of cysts were found occurring in two or more of the visceral organs of animals slaughtered (Table 2).

Table 1: Prevalence of Cysticercus tenuicollis in different age groups of sheep slaughtered at Jimma municipal abattoir

\begin{tabular}{lcccccc}
\hline Age group & $\begin{array}{c}\text { Number of } \\
\text { Examined }\end{array}$ & Prevalence (\%) & $\mathbf{9 5 \%}$ CI & df & $\mathbf{X}^{\mathbf{2}}$ & P-Value \\
\hline Adult & 274 & $170(62.0)$ & $56.0-68.0$ & 1 & 28.81 & 0.000 \\
Young & 110 & $35(31.8)$ & $22.0-40.0$ & & & \\
\hline Total & 384 & $205(53.4)$ & $48.0-58.0$ & & & \\
\hline
\end{tabular}

Table 2: Distribution of Cysticercus tenuicollis in the visceral organs of Sheep slaughtered at Jimma municipal abattoir

\begin{tabular}{cccc}
\hline $\begin{array}{c}\text { Number of } \\
\text { animals } \\
\text { examined }\end{array}$ & $\begin{array}{c}\text { Visceral organs } \\
\text { affected }\end{array}$ & $\begin{array}{c}\text { Number of animals harboring } \\
\text { Cysticercus tenuicollis }\end{array}$ & Proportion (\%) \\
\hline \multirow{3}{*}{384} & Liver & 98 & 25.5 \\
& Mesentery & 61 & 15.9 \\
& Omentum & 146 & 38.0 \\
\hline
\end{tabular}

In this study a preliminary estimate of direct financial loss incurred from liver condemnation in sheep due to C. tenuicollis was determined. Accordingly, based on estimated average mean annual slaughter rate of 3840 heads of sheep at Jimma abattoir, the average rejection rate of liver from a total of 384 studied animals was $75(19.53 \%)$ and also considering the mean current local market price of a single liver at Jimma, an estimated financial loss of 21528 ETB was inevitable.

\section{DISCUSSION}

The present investigation showed a high prevalence of $C$. Tenuicollis $(53.4 \%)$ in sheep slaughtered in Jimma Municipal abattoir. This was in line with the findings of Wondimu et al., (2011) who reported 56.8\% from HELMEX, Debezeit. However, it was relatively higher when compared to the finding of Mekuria et al., (2013) from Dire Dawa municipal abattoir and Abebe et al., (2014) from Dessie Manicipal Abattoir, who reported $22.8 \%$ and $45.69 \%$ respectively. It was also higher than the reports from other countries; for instance, $13.1 \%$ from Nigeria (Saulawa et al., 2011), 24\% from Turkey (Senilk, 2008), 16.7\% from Germny (Hasslinger and Weber-Werringhen, 1988) and 23.27\% from Egypt (El-Masry, 1986). Furthermore; it was lower than the findings of Sissay et al., (2008) who reported 79\% from four abattoirs located in eastern part of Ethiopia. This difference in prevalence of C.tenuicollis in the different locations could be due to the variations in temperature, agro-ecology, the degree of pasture contamination, the presence of stray dogs on the farm and the access of dogs to infected visceral organs. which may favors perpetuation of the life cycle of this parasite between ruminants, dogs and other wild canids.

According to the present study, prevalence of $C$. tenuicollis by age revealed that higher infestation rates 
were recorded in adult sheep (62\%), whereas, the lowest prevalence ware recorded in younger sheep (31.8\%). This was agreed with the findings of Abdulatif et al., (2015) who reported a prevalence of 54.3\% in adult sheep and $43 \%$ in young sheep. Similar findings also reported by Woinshet and Girma (2010) who recorded the prevalence of $47.4 \%$ in adult sheep and $35.8 \%$ in young sheep. This difference in infection rates between young and adult may be due to the fact that the adult sheep lived longer and picked larger number of eggs during grazing as compared to the young ones, which only lived for a shorter period of time in a given environment and mostly kept indoors.

According to the present study, from those infected animals the cyst mostly found in omentum( $(38 \%)$, followed by liver( $25.5 \%)$, mesentery $(15.9 \%)$, and peritoneum $(7.8 \%)$. This agreed with the observation of Wondimu et al., (2011), Samuel and Zewde (2010), Radfar et al., (2005) and Senlik (2008) who reported that omentum is the predominant predilection sites for $C$. tenuicollis. This may be due to the fact that omentum covers larger surface area in the peritoneal cavity than other tissues.

The total direct financial losses due to $C$. tenuicollis in sheep at Jimma municipal abattoir was estimated to be 861.12 US dollar (USD) i.e. approximately 21,528 ETB. This result was lower than from the previous reports; for instance, the estimated total losses from $C$. tenuicollis in small ruminants due to liver condemnation in Helmex abattoirs were 65,269.89 USD (Wondimu et al., 2011). The difference in the amount of economic losses could be due to the variation in the number of species slaughtered in the abattoir (this calculated only for sheep), frequency of liver infested, mean annual slaughter rate of the abattoir and variation in the retail market price of organs of different country. Such loses are particular importance in Ethiopia, which has low economic output where sheep and goat production are the major livestock industries.

\section{CONCLUSION AND RECOMMENDATIONS}

This study revealed high prevalence of Cysticercus tenuicollis in sheep slaughtered at Jimma municipal abattoir. The preferred predilection sites of Cysticercus tenuicollis were liver, omentum, mesentery and peritoneum, and of this omentum was the predominantly preferred organ. This high prevalence of Cysticercus tenuicollis in the study area predominantly cause liver condemnation with a consequent of high financial losses observed at Jimma abattoir. Therefore, based on this finding the following recommendations are suggested.

- All condemned organs should be properly disposed to avoid access by carnivorous animals.

- Regular dog deworming programs should be designed to avoid environmental contamination with the eggs of patent parasites.

- Awareness creation programs may be organized for animal owners, butchers and abattoir workers to limit the prevalence of Cysticercus tenuicollis in Jimma area.

\section{REFERANCE}

Abdulatif, A., Kebede, A. and Mammo, B. (2015): Prevalence, cyst distribution in visceral organs and economic loss of Cysticercus tenuicollis in small ruminants slaughtered at Bishoftu, Elfora Export Abattoir. Am-Euras. J. Sci. Res., 10 (4): 210-220.

Abduljewad, A. (1988). Hydatidosis prevalence at Jimma Abattoir. DVM thesis, Faculty of Veterinary Medicine, Addis Ababa University. Veterinary Medicine, Addis Ababa University.

Budka, H., Buncic, S., Colin, P. and Collins, J. (2004): Opinion of the scientific panel on biological hazards on a request from the commission related on revision of meat inspection procedures for lambs and goats. EFSA J, 54: $1-49$.

Abebe, G. (1995): Current status of veterinary education and animal health research in Ethiopia. In: Veterinary medicine impact on human health and nutrition in Africa. Proceeding of an international conference ILRI, Addis Ababa, Pp. 133-138.

Abebe, T., Belay, M., Shahid, N., and Assefa A. (2014): Majoretacestodes in small ruminants slaughtered at Dessie municipal abattoir, Eastern Ethiopia: prevalence, cyst viability, organ distribution and economic implications, London, j. Comp. Clin. Pathol, Pp 253-275.

Budka, H., Buncic, S., Colin, P. and Collins, J. (2004): Opinion of the scientific panel on biological hazards on a request from the commission related on revision of meat inspection procedures for lambs and goats. EFSA J, 54: $1-49$.

CSA, 2009. Agricultural survey. Report on livestock, poultry and bee hives population, private peasant holdings. Addis Ababa, Ethiopia, pp: 2.

El- Masry AAN (1986). Morphobiological studies on the larval stages of some cestodes. MVSc. Thesis, Faculty of Veterinary Medicine, Cairo University.

FAO, 1994. Meat inspection manual for developing countries, Rome, Italy, pp: 12-14.

Getanby, R. (1991): Sheep: In the tropical agriculturalist. Macmillan, TCTA, Pp. 6-10.v

Hasslinger, M.A. and Weber -werringhen, R. (1988): Faecal tests of sheep on pasture and prevalence of Cysticercus tenuicollis in slaughtered sheep. Angewandte Parasitol. 29: 227-234. Helminthes parasites of 
ruminants. ILRAD, Nairobi, Kenya, p. 150.

Herenda, D., Chambers, P.G., Ettriqui, A., Seneviratna, P., da Silva, T.J.P. (2000): Manual on meat inspection for developing countries, Pp. 30-50.

JZARDO, (2009). Jimma zone agriculture and rural developmental office.

Mekuria, E., Shimelis, S., Bekele, J. and Sheferaw, D. (2013): Sheep and goats Cysticercus tenuicollis prevalence and associated risk factors, Afri. J. of Agri. Res., 8(24): 3121-3125.

Ogunrinade, A., Ogunrinade, B. (1980): Economic importance of bovine fasciolosis in Nigeria. Anim. Health Prod., 12(3): 155-159.

Perry, B.D., Randolph, R.F., Mc Dermott, Sones, K.R., and Thornton, P.K. (2002): Investing in animal health research to alleviate poverty. International Livestock Research Institute (ILRI), Nairobi, Kenya, Pp.148.

Radfar, M., Tajalli, S., Talalzadeh, M. (2005): Prevalence and morphological characterization of Cysticercus tenuicollis (Taenia hydatigena cystcerci) from sheep and goats in Iran. Vet. Arch., 75: 469-476.

Radostits, O.M., Gay, C.C., Blood, D.C. and Hencheliff, K.W. (2007): Veterinary medicine, a text book of diseases of cattle, sheep, goats, pig and horses, 9th ed., London: Bailliere Tindall, Pp:1378-1383.

Samuel, G. And Zewde, G.G. (2010): Prevalence, risk factors, and distribution of C. tenuicollis in visceral organs of slaughtered sheep and goats in central Ethiopia. Trop. Anim. Health Prod., 42:1049-1051.

Saulawa, M., Magaji, A., Faleke, O., Mohammed, A., Kudi, A., Musawa, A., Sada, A., Ugboma, A., Akawu,B., Sidi, S., Lawal, N. and Ambursa, A. (2011): Prevalence of Cysticercus tenuicollis cysts in sheep slaughtered at Sokoto abattoir, Sokoto state, Nigeria. Sokoto Journal of Veterinary Sciences, 9(2): 24-27.

Senlik, B. (2008): Influence of host breed, sex and age on the prevalence and intensity of C. tenuicollis in sheep. J. Anim. Vet. Adv., 7(5):548-551.

Sisay M. (2007): Helminth Parasites of Sheep And Goats in Eastern Ethiopia. Epidemiology and Anthelmintic Resistance and its Management. Faculty of Veterinary Medicine and Animal Science. Department of Biomedical Sciences and Veterinary Public Health Division of Parasitology and Virology Uppsala Sweden Doctoral thesis Swedish University of Agricultural Sciences, 2007: Pp: 11-12.

Thrusfield, M. (2005): Veterinary Epidemiology. Oxford, Black Well Science, publishing Ltd., 2: 88.

Urquhart, G., Armour, J., Duncan, J., Dunn, A., Jennings, F. (1996): Department of Veterinary Parasitology, FVM, The University of Glasgow, Scotland, Pp. 122.

Wondimu, A., D. Abera and Y. Hailu, 2011. A study on the prevalence, distribution and economic importance of Cysticercustenuicollis in visceral organs of small ruminants slaughtered at an abattoir in Ethiopia. JVAMH, 3(5): $67-74$

Woinshet, S. and Girma, G. (2010): Prevalence, risk factors and distribution of Cysticercus tenuicollis in visceral organs of slaughtered sheep and goats in central Ethiopia. Trop Anim Health Prod, 42:1049-1051.

Yehualashet, B., Aklilu, A., Kaleab, Z. and Tsegaye, A. (2012): Prevalence and economic importance of liver parasites: Hydatid Cyst, Fasciola species and Cysticercus tenuicolis in sheep and goats slaughtered at Addis Ababa abattoir enterprise in Ethiopia. J.Vet.Med. and Anim. Health, 5(1):1-7 